\title{
Crescimento e rendimento do milho sob interferência da tiririca
}

\section{Growth and yield of maize in purple nutsedge interference}

\author{
Daniel Valadão Silva ${ }^{1 *}$; Marco Antonio Moreira de Freitas²; \\ Gustavo Soares da Silva ${ }^{3}$; Matheus de Freitas Souza ${ }^{3}$; Antonio Alberto da Silva \\ Lino Roberto Ferreira ${ }^{4}$; Tocio Sediyama ${ }^{4}$; Paulo Roberto Cecon ${ }^{5}$
}

\section{Resumo}

Objetivou-se neste trabalho avaliar a interferência da tiririca (Cyperus rotundus) sobre o crescimento e rendimento de grãos da cultura do milho. O experimento de campo foi realizado sob o delineamento experimental inteiramente ao acaso, com três repetições. Os tratamentos foram constituídos do convívio do milho com nove densidades de tiririca $(0,10,30,50,90,110,130,160$ e 260 manifestações epígeas $\mathrm{m}^{-2}$ ). No florescimento da cultura fez-se a medição da altura das plantas, da inserção das espigas e a massa seca total das plantas de milho. Por ocasião da colheita foram determinados a massa de espigas, o rendimento de grãos e a massa de 100 grãos. O incremento da densidade de tiririca aumentou a altura de plantas e de inserção da primeira espiga do milho. Observou-se também redução no acúmulo de massa seca total, na massa de espigas e de 100 grãos e na produtividade do milho em todas as densidades avaliadas. A interferência da tiririca reduz o crescimento do milho com consequências diretas na produtividade de grãos da cultura.

Palavras-chave: Cyperus rotundus, Zea mays, competição, produtividade

\begin{abstract}
This research aimed evaluates the influence of purple nutsedge (Cyperus rotundus) on the agronomic performance of maize. We conducted a field experiment at Viçosa, MG, in completely randomized design experimental with three replications. The treatments consisted of the interaction of maize with nine nutsedge densities $\left(0,10,30,50,90,110,130,160\right.$ and 260 plants $\left.\mathrm{m}^{-2}\right)$. In the flowering culture was made the measurement of plant height, the insertion of the corn ears and the total dry matter of corn plants. At harvest were determined ear weight, grain yield and 100-grain weight adjusted to $13 \%$ moisture. Higher density of nutsedge increased plant height and the insertion of the first corn ear. We also observed a reduction in total dry matter accumulation, ear weight, 100-grain weight and grain yield in all densities evaluate. Nutsedge control, even at low densities is necessary because the presence of this plant promotes negative effect on growth and development of corn with a direct consequences on crop productivity.
\end{abstract}

Key words: Cyperus rotundus, Zea mays, competition, productivity

1 Dr. em Fitotecnia, Eng ${ }^{\circ}$ Agr $^{\circ}$, Universidade Federal Rural do Semi-Árido, UFERSA, Mossoró, RN. E-mail: danielvaladaos@, yahoo.com.br

2 Dr. em Fitotecnia, Eng ${ }^{\mathrm{o}}$ Agr ${ }^{\circ}$, Instituto Federal Goiano, IFGOIANO, Posse, GO. E-mail: marco.freitas@ifgoiano.edu.br

3 Discentes do Curso de Mestrado do Programa de Pós-Graduação em Fitotecnia, Universidade Federal de Viçosa, UFV, Viçosa, MG. E-mail: gustavusoares@hotmail.com; freitasouza@yahoo.com.br

${ }^{4}$ Eng $^{\text {os }}$ Agros ${ }^{\text {s }}$, Dr. em Fitotecnia, Dept ${ }^{\mathrm{o}}$ de Fitotecnia, UFV, Viçosa, MG. E-mail: aasilva@ufv.br; lroberto@ufv.br; t.sediyama@ ufv.br

${ }^{5}$ Eng $^{\circ}$ Agr ${ }^{\circ}$, Dr. em Fitotecnia, Dept ${ }^{\circ}$ de Estatística, UFV, Viçosa, MG. E-mail: cecon@ufv.br

* Autor para correspondência 
A ocorrência de plantas daninhas na cultura do milho provoca perdas que não se limitam unicamente à produtividade de grãos, mas também interferem sobre outros fatores de produção economicamente importantes como a qualidade de silagem e grãos (JAKELAITIS et al., 2004) e na eficiência da colheita (KARAM; MELHORANÇA, 2002).

A tiririca (Cyperus rotundus) é considerada uma das principais plantas daninhas que ocorrem no ecossistema agrícola mundial, sendo encontrada em 92 países e em mais de 50 culturas (DAS; YADURAJU, 2008). A importância dessa espécie como infestante de culturas agrícolas baseiase em características ecológicas relacionadas aos mecanismos de reprodução, distribuição generalizada e dificuldade de controle (HOLM et al., 1991). É uma planta daninha perene, que se multiplica rapidamente por meio de rizomas, bulbos ou de uma extensa rede de tubérculos subterrâneos com forte dominância apical (NELSON; RENNER, 2002; WEBSTER et al., 2008).

A capacidade de suportar a competição imposta por outra planta varia entre as diferentes espécies. Segundo Carvalho et al. (2011) o milho pode ser considerado uma cultura com boa capacidade competitiva com as plantas daninhas por se enquadrar no grupo daquelas que mais rapidamente sombreiam o solo. Diferente do milho, a tiririca apresenta porte baixo e é sensível ao sombreamento, sendo o manejo da luminosidade uma das ferramentas de maior importância no manejo integrado dessa planta daninha (JAKELAITIS et al., 2003), embora seja caracterizada como planta de crescimento rápido em condições favoráveis (alta temperatura e luminosidade).

A predição das perdas das culturas pela competição com as plantas daninhas é uma das formas de auxiliar o produtor na decisão de controlar ou não determinada espécie. A ocorrência de tiririca já foi relatada como causa da redução da produtividade de milho (WILLIAM; WARREN, 1975; STOLLER; WAX; SLIFE, 1979; KONDAP et al., 1982; KEELEY, 1987). No entanto, há pouca informação a cerca dos impactos de diferentes densidades de tiririca sobre os componentes produtivos do milho em ambiente tropical.

A hipótese deste trabalho é que o aumento da densidade de tiririca afeta negativamente as características agronômicas do milho. Assim, objetivou-se determinar o efeito de populações de tiririca (Cyperus rotundus) sobre o crescimento e produtividade do milho.

O experimento foi realizado em campo (altitude: $648,74 \mathrm{~m}$; latitude: $20^{\circ} 45^{\prime} 14^{\prime \prime} \mathrm{S}$; longitude: 42 52 ' 53 ' W; coordenadas UTM (m): 7.703 .630 $\mathrm{N}$ e $720.570 \mathrm{E})$. O solo da área experimental foi classificado como Argissolo Vermelho-Amarelo Câmbico, de textura argilosa $(43 \%, 14 \%$ e 43\% de argila, silte e areia, respectivamente), que apresentava as seguintes características químicas: 5,6 de pH em água ; 2,6 dag $\mathrm{kg}^{-1}$ de matéria orgânica; 5,9 $\mathrm{mg} \mathrm{dm}^{-3}$ de P; $64 \mathrm{mg} \mathrm{dm}^{-3}$ de $\mathrm{K}$; e Ca, $\mathrm{Mg}, \mathrm{H}$ $+\mathrm{Al}$ e t iguais a 2,$0 ; 0,8 ; 3,3$; e $2,96 \mathrm{cmol}_{\mathrm{c}} \mathrm{dm}^{-3}$, respectivamente. Os índices pluviométricos e as temperaturas médias semanais ocorridas durante o período experimental estão apresentados na Figura 1 .

O preparo do solo foi realizado com uma aração e duas gradagens sete dias antes da semeadura do milho que ocorreu em 20 de outubro de 2012. O híbrido DKB 390 foi semeado no espaçamento entre fileiras de $0,50 \mathrm{~m}$ e população de plantas de 60000 pl. ha-1.

A adubação de semeadura constou de 400 $\mathrm{kg} \mathrm{ha}^{-1}$ do adubo formulado 8-28-16 (N-P-K) na linha, sendo a adubação de cobertura realizada aos 30 dias após a emergência (DAE), aplicando-se o equivalente a $90 \mathrm{~kg} \mathrm{ha}^{-1}$ de nitrogênio na forma de ureia.

Os tratamentos foram constituídos de nove densidades de tiririca $(0,10,30,50,90,110,130$, 160 e 260 pl. $\mathrm{m}^{-2}$ ) dispostos em delineamento inteiramente casualizados, com três repetições. Cada planta foi referente a uma manifestação epígea 
da planta daninha. Cada parcela experimental foi composta por 10 linhas de milho com 6 metros de comprimento espaçadas de $0,50 \mathrm{~m}$. Como área útil foi considerada as 6 linhas centrais, excluindo $1 \mathrm{~m}$ de cada borda, totalizando $12 \mathrm{~m}^{2}$.

Figura 1. Temperatura e precipitação pluvial média semanal do período experimental. Viçosa, MG.

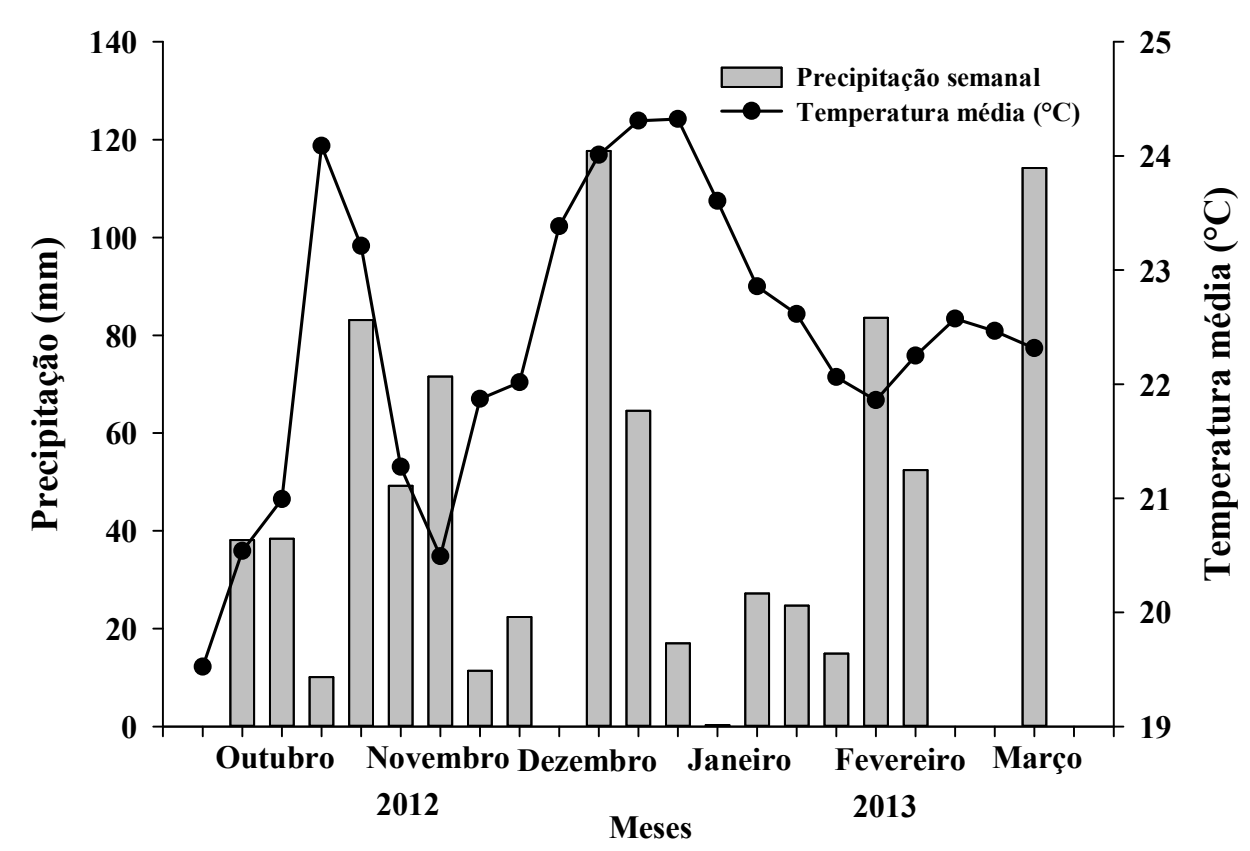

Fonte: Elaboração dos autores.

A distribuição dos tratamentos (densidades de tiririca) nas parcelas experimentais foi realizada aos 15 DAE, após contagem da população de tiririca em cada parcela. Para essa contagem utilizou-se quadrado metálico com $0,25 \mathrm{~m}^{-2}$ que foi lançado ao acaso quatro vezes na parcela para fazer a amostragem da área, onde se fez a contagem do número de plantas de tiririca. Assim selecionaramse parcelas uniformes, conforme a densidade de plantas desejada. Aos 15, 30 e 45 DAE foi realizado desbaste em cada parcela para manutenção da densidade de cada tratamento. O controle das outras espécies de plantas daninhas foi realizado com a aplicação da mistura em tanque dos herbicidas nicossulfuron $\left(24 \mathrm{~g} \mathrm{ha}^{-1}\right)$ e atrazine $\left(1.500 \mathrm{~g} \mathrm{ha}^{-1}\right)$ aos 20 dias após a semeadurado milho. Na testemunha isenta de tiririca, além do controle químico, fez o complemento com enxada, quando necessário.
$\mathrm{Na}$ ocasião do florescimento do milho foi realizada a medição da altura de planta e da inserção da espiga de 10 plantas de milho, escolhidas ao acaso na área útil da parcela.

Para avaliar o acúmulo de massa seca do milho foram colhidas, aos 130 DAE, 10 plantas de milho que foram secas em estufa de circulação forçada de ar à $65^{\circ} \mathrm{C}$ até atingir massa constante e, em seguida pesadas.

A colheita foi realizada aos 160 DAE, ocasião em que foram determinados o estande final de plantas, a massa de espigas, o rendimento de grãos e a massa de 100 grãos corrigidos para $13 \%$ de umidade.

Os dados foram submetidos à análise de variância pelo teste $\mathrm{F}$ e análise de regressão. As escolhas dos modelos de regressão foram baseadas na significância dos coeficientes $(p \leq 0,05)$, no 
coeficiente de determinação e no comportamento biológico do fenômeno.

A precipitação pluvial foi bem distribuída no período da realização do experimento e não foi limitante para o desenvolvimento e crescimento do milho e da tiririca (Figura 1). Desta maneira, os resultados encontrados foram expressão direta da interferência da tiririca sobre a cultura.

A altura das plantas de milho aumentou linearmente com o incremento das plantas de tiririca (Figura 2a). Comportamento semelhante foi observado para a altura de espigas do milho, mas com tendência a estabilização em densidades próximas a $200 \mathrm{pl} \mathrm{m}^{-2}$ (Figura $2 \mathrm{~b}$ ). $\mathrm{O}$ aumento da altura do milho pode estar relacionado com mecanismos de escape ao sombreamento da cultura, que tende a aumentar sua estatura como forma de sobressair à planta daninha na competição por luz (LAMEGO et al., 2015). Esse efeito pode ter influenciado diretamente no aumento da altura da espiga. Essas características não são desejadas, pois estão diretamente relacionadas com a tolerância ao acamamento do milho (LI et al., 2007). Isso ocorre porque a alta relação inserção/estatura pode diminuir o centro de gravidade da planta, provocando o acamamento. Vale ressaltar que no presente trabalho não foi constatado acamamento das plantas de milho na área experimental.

A presença de plantas de tiririca reduziu a massa seca da tiririca, independente da densidade da planta daninha (Figura 2c). Esse resultado pode estar relacionado com a competição por água e nutrientes promovida pela tiririca. Segundo Morales-Payan et al. (2003) a tiririca é uma espécie daninha que exerce maior competição por recursos encontrados abaixo da superfície do solo, devido à inabilidade da planta em sombrear a cultura.

A massa de 100 grãos do milho foi reduzida pela interferência da tiririca, mesmo nas menores densidades da planta daninha (Figura 2d). A competição por nutrientes entre a tiririca e o milho pode ter influenciado na redução da massa dos grãos do milho, visto que alguns nutrientes, como o nitrogênio, podem alterar diretamente nesta característica (BORTOLINI et al., 2001). Além disso, Sangoi (2001) relata que a competição das plantas pela radiação solar incidente, por nutrientes e por água determina a formação da espiga, sobretudo em suprimento de carbono e nitrogênio para as plantas. Consequentemente pode haver um incremento da esterilidade das plantas e um decréscimo do número de grãos por espiga e, também, da massa dos grãos. Isso provoca a redução no desenvolvimento dos grãos, notadamente na parte superior da espiga, que, muitas vezes, não se desenvolve, ainda que tenha havido fertilização regular dos óvulos.

A massa de espiga do milho foi reduzida pela presença da tiririca (Figura 3a). A convivência do milho com $10 \mathrm{pl} \mathrm{m}^{-2}$ de tiririca causou redução de aproximadamente $10 \%$ da massa da espiga. Esses valores corroboram com os observados por Rossi et al. (1996) que também relaram redução da massa de espiga de sete cultivares de milho nas parcelas sem o controle das plantas daninhas e podem estar relacionado a redução da massa dos grãos.

Quanto à produtividade de grãos de milho verificou-se redução da variável ocasionada pela presença da tiririca (Figura 3b). A redução na produtividade foi próxima a $10 \%$ na presença de $10 \mathrm{pl} \mathrm{m}^{-2}$, o que corresponde a aproximadamente 16 sacas de 60 quilos de milho.

Diversos autores encontraram correlação direta entre a perda de produtividade de culturas e o número de plantas de tiririca encontradas em áreas de cultivo (WILLIAM; WARREN, 1975; STOLLER; WAX; SLIFE, 1979; KEELEY, 1987; JOHNSON; MULLINIX, 1999). Para o milho, Kondap et al. (1982) relataram que a presença da tiririca reduziu em $6 \%$ a produção de milho enquanto que Stoller, Wax e Slife (1979) observaram redução de 8\% em densidade de $100 \mathrm{pl} \mathrm{m}^{-2}$ de C. esculentus. Todavia, já foi relatado que a tiririca em densidades de 200 a $500 \mathrm{pl} \mathrm{m}^{-2}$ pode reduzir o rendimento do milho em até $79 \%$ (KEELEY, 1987). 
Figura 2. Altura de plantas (a), altura de inserção da primeira espiga (b), massa seca da parte aérea (c) e massa de 100 grãos (d) de milho em função de diferentes densidades de tiririca.
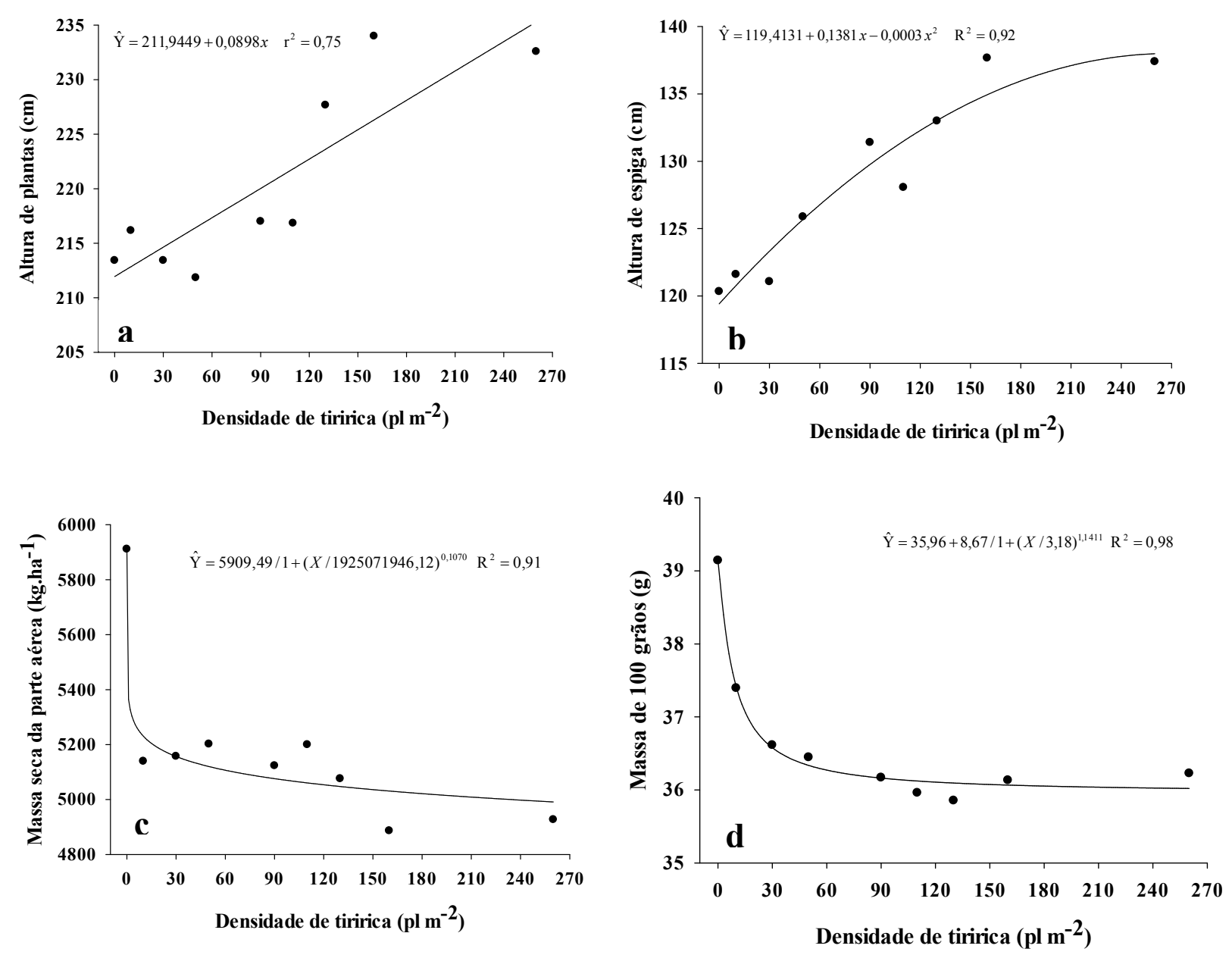

Fonte: Elaboração dos autores. 
Figura 3. Massa de espigas (a) e produtividade de grãos do milho (b) em função de diferentes densidades de tiririca.
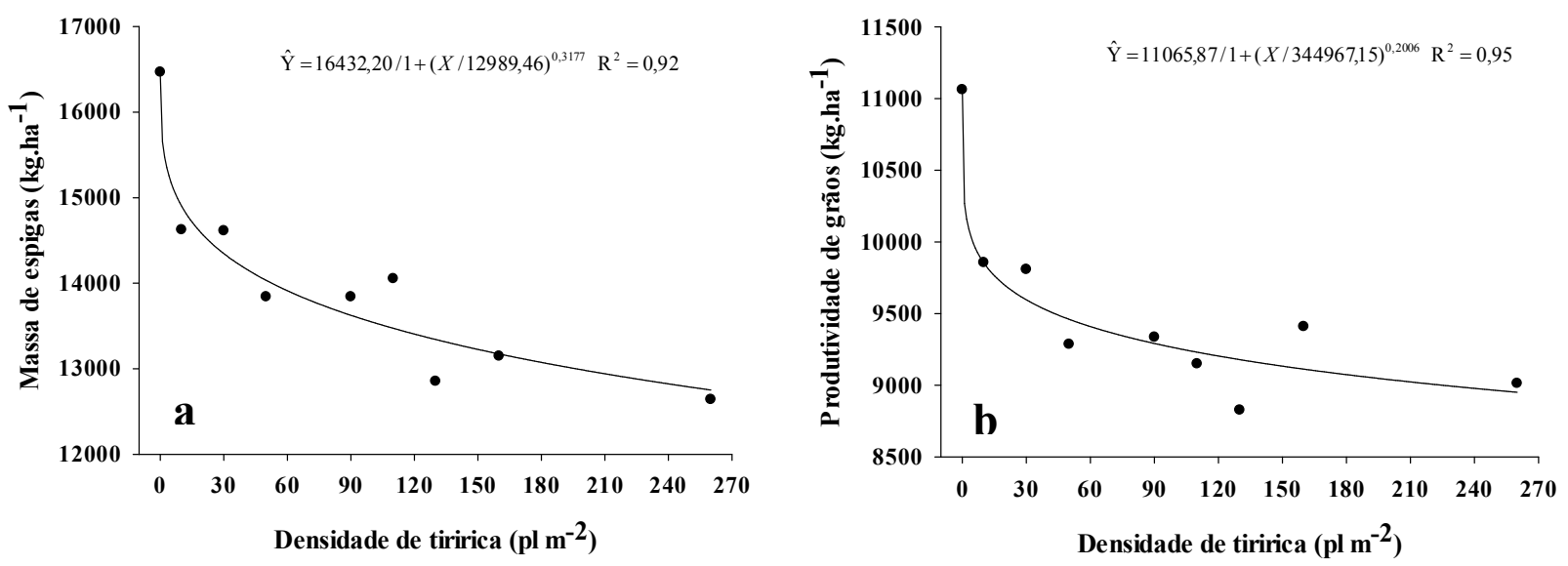

Fonte: Elaboração dos autores.

Os diferentes valores referentes à redução da produção do milho sob interferência da tiririca pode estar relacionado com as condições em que cada ensaio foi conduzido. Na presente pesquisa, a semeadura do milho foi realizada no espaçamento entre linhas de $0,50 \mathrm{~m}$ o que contribuiu no menor tempo para a cobertura do solo e consequentemente sombreou a tiririca reduzindo sua capacidade de competir com a cultura. Segundo Bullock, Nielsen e Nyquist (1988) a redução do espaçamento contribui para um uso mais eficiente da luz disponível e também para sombrear a superfície do solo de forma mais completa principalmente na fase inicial de crescimento da cultura.

A tiririca é uma planta daninha caracterizada pela facilidade de se propagar vegetativamente por meio de bulbos, rizonas e, sobretudo por tubérculos. Essa grande presença de estruturas vegetativas no solo pode auxiliar a planta daninha na competição por água e nutrientes. Vale ressaltar que, no presente trabalho analisaram-se somente os efeitos causados pelas manifestações epígeas da tiririca, que são apenas manifestações destas estruturas localizadas no solo. Desta maneira, em futuros estudos sobre a interferência desta planta daninhas sobre o milho recomenda-se que também seja avaliada a quantidade de estruturas vegetativas presentes no solo e sua relação com os resultados encontrados.

O controle da tiririca, mesmo em baixas densidades, é necessário, pois a presença desta planta promove efeito negativo no crescimento do milho com consequências diretas na produtividade de grãos da cultura.

Os autores agradecem ao Conselho Nacional de Desenvolvimento Científico e Tecnológico (CNPq), ao Fundação de Amparo à Pesquisa do Estado de Minas Gerais (FAPEMIG) e a Coordenação de Aperfeiçoamento de Pessoal de Nível Superior (CAPES) pelo financiamento e suporte para a execução do trabalho.

\section{Referências}

BORTOLINI, C. G.; SILVA, P. R. F.; ARGENTA, G.; FORSTHOFER, E. L. Rendimento de grãos de milho cultivado após aveia-preta em resposta a adubação nitrogenada e regime hídrico. Pesquisa Agropecuária Brasileira, Brasília, v. 36, n. 9, p. 1101-1106, 2001.

BULLOCK, D. G.; NIELSEN, R. L.; NYQUIST, W. E. A. growth analysis comparison of corn grown in conventional and equidistant plant spacing. Crop Science, Madison, v. 28, n. 2, p. 254-258, 1988. 
CARVALHO, F. P.; SANTOS, J. B.; CURY, J. P.; VALADÃO SILVA, D.; BRAGA, R. R.; BYRRO, E. C. M. Alocação de matéria seca e capacidade competitiva de cultivares de milho com plantas daninhas. Planta Daninha, Viçosa, MG, v. 29, n. 2, p. 373-382, 2011.

DAS, T. K.; YADURAJU, N. T. Effect of soil solarization and crop husbandry practices on weed species competition and dynamics in soybean e wheat cropping system. Indian Journal Weed Science, New Deli, v. 40, n. 1, p. 1-5, 2008

HOLM, L. G.; PLUCKNETT, D. G.; PANCHO, J. V.; HERBERGER, J. P. The world's worst weeds, distribution and biology. Malabar: Krieger Publishing Co., 1991. 550 p.

JAKELAITIS, A.; FERREIRA, L. R.; SILVA, A. A.; AGNES, E. L.; MIRANDA, G. V.; MACHADO, A. F. L. Efeitos de sistemas de manejo sobre a população de tiririca. Planta Daninha, Viçosa, MG, v. 21, n. 1, p. 8995, 2003.

JAKELAITIS, A.; SILVA, A. A.; FERREIRA, L. R.; SILVA, A. F.; FREITAS, F. C. L. Manejo de plantas daninhas no consórcio de milho com capim-braquiária (Brachiaria decumbens). Planta Daninha, Viçosa, MG, v. 22, n. 4, p. 553-560, 2004.

JOHNSON, W. C.; MULlinIX, B. G. Cyperus esculentus interference in Cucumis sativus. Weed Science, Washington, v. 47, n. 3, p. 327-331, 1999.

KARAM, D.; MELHORANÇA, A. L. Cultivo do milho: plantas daninhas na cultura do milho. Sete Lagoas: EMBRAPA Milho e Sorgo, 2002. 10 p. (Comunicado técnico, 58).

KEELEY, P. E. Interference and interaction of purple and yellow nutsedges (Cyperus rotundus and C. esculentus) with crops. Weed Technology, Washington, v. 1, n. 1, p. 74-81, 1987.

KONDAP, S. M.; RAMAKRISHNA, K.; REDDY, G. B.; RAO, A. N. Investigations on the competitive ability of certain crops against purple nutsedge (Cyperus rotundus L.). Indian Journal of Weed Science, New Delhi, v. 14, n. 2, p. 124-126, 1982.
LAMEGO, F. P.; REINEHR, M.; CUTTI, L.; AGUIAR, A. C. M.; RIGON, C. A. G.; PAGLIARINI, I. B. Alterações morfológicas de plântulas de trigo, azevém e nabo quando em competição nos estádios iniciais de crescimento. Planta Daninha, Viçosa, MG, v. 33, n. 1, p. 13-22, 2015.

LI, Y.; DONG, Y.; NIU, S.; CUI, D. The genetics relationships among plant-height traits found using multiple trait QTL mapping of a dent corn and popcorn cross. Genome; Toronto, v. 50, n. 4, p. 357-364, 2007.

MORALES-PAYAN, J. B.; STALL, W. M.; SHILLING, D. G.; CHARUDATTAN, R.; DUSKY, J. A.; THOMAS, A. Bewick above- and below-ground interference of purple and yellow nutsedge (Cyperus spp.) with tomato. Weed Science, Washington, v. 51, n. 2, p. 181-185, 2003.

NELSON, K. A.; RENNER, K. A. Yellow nutsedge (Cyperus esculentus) control and tuber production with glyphosate and ALS inhibiting herbicides. Weed Technology, Washington, v. 16, n. 3, p. 512-519, 2002.

ROSSI, I. H.; OSUNAS, J. A.; ALVES, P. L. C. A.; BEZUTTE, A. J. Interferência das plantas daninhas sobre algumas características agronômicas e a produtividade de sete cultivares de milho. Planta Daninha, Viçosa, MG, v. 14, n. 2, p. 134-148, 1996.

SANGOI, L. Understanding plant density effects on maize growth and development: an important issue to maximize grain yield. Ciência Rural, Santa Maria, v. 31, n. 1, p. 159-168, 2001.

STOLLER, E. W.; WAX, L. M.; SLIFE, F. W. Yellow nutsedge (Cyperus esculentus) competition and control in corn (Zea mays). Weed Science, Washington, v. 27, n. 1, p. 32-37, 1979.

WEBSTER, T. M.; GREY, T. L.; DAVIS, J. W.; CULPEPPER, A. S. Glyphosate hinders purple nutsedge (Cyperus rotundus) and yellow nutsedge (Cyperus esculentus) tuber production. Weed Science, Washington, v. 56, n. 4, p. 735-742, 2008.

WILlIAM, R. D.; WARREN, G. F. Competition between purple nutsedge and vegetables. Weed Science, Washington, v. 23, n. 4, p. 317-323, 1975. 
